\title{
Hydrogen Desorption Spectra from Excess Vacancy-Type Defects Enhanced by Hydrogen in Tempered Martensitic Steel Showing Quasi-cleavage Fracture
}

\begin{abstract}
KEI SAITO, TETSUYA HIRADE, and KENICHI TAKAI
An attempt was made to separate and identify hydrogen peaks desorbed from plastic-strained, hydrogen-enhanced lattice defects from among various trapping sites in tempered martensitic steel showing quasi-cleavage fracture using thermal desorption spectroscopy from a low temperature (L-TDS) and positron annihilation spectroscopy (PAS). The amount of the lattice defects beneath the quasi-cleavage fracture surface was measured by L-TDS. The L-TDS results made it possible to separate two peaks, namely that of the original desorption and also that of new desorption from the steel specimens due to the application of plastic strain in the presence of hydrogen. The PAS results revealed that the new desorption obtained by L-TDS corresponded to vacancy-type defects. Hydrogen and plastic strain noticeably enhanced lattice defects formed within $1.5 \mathrm{~mm}$ from the fracture surface, where the average concentration of vacancy-type defects reached approximately $10^{-5}$ order in terms of atomic ratio. These results indicate that the accumulation of excess vacancy-type defects enhanced by hydrogen in the local region can lead to nanovoid nucleation and coalescence in plastic deformation, resulting in quasi-cleavage fracture of tempered martensitic steel.
\end{abstract}

https://doi.org/10.1007/s11661-019-05450-3

(c) The Minerals, Metals \& Materials Society and ASM International 2019

\section{INTRODUCTION}

HiGH-STRENGTH steels are required for making lightweight automobile parts and structural products. Degradation of the mechanical properties of highstrength steels due to hydrogen embrittlement (HE) is a crucial challenge for maintaining the safety of automobile parts and structural products. Since susceptibility of $\mathrm{HE}$ increases with increasing strength of steels, clarification of the HE mechanism is necessary for expanding the application of high-strength steels.

Many studies have been conducted for that purpose and some promising mechanisms have been proposed concerning the direct or indirect effects of hydrogen on the degradation of metals. ${ }^{[1-8]}$ Hydrogen directly reduces the cohesive energy of lattice bonding, which

KEI SAITO is with the Graduate School of Science and Technology, Sophia University, Tokyo 102-8554, Japan and also with Nissan Motor Co., Ltd., Kanagawa 243-0192, Japan. TETSUYA HIRADE is with the Nuclear Science and Engineering Center, Japan Atomic Energy Agency, Ibaraki 319-1195, Japan. KENICHI TAKAI is with the Department of Engineering and Applied Sciences, Faculty of Science and Technology, Sophia University, Tokyo 102-8554, Japan. Contact e-mail: takai-k@sophia.ac.jp

Manuscript submitted March 22, 2019.

Article published online September 11, 2019 has been called the hydrogen-enhanced decohesion model (HEDE). ${ }^{[1,2]}$ One of the models of indirect hydrogen effects is hydrogen-enhanced localized plasticity (HELP), in which hydrogen weakens the interaction between two dislocations and promotes dislocation motion, resulting in mature fracture. ${ }^{[3-5]}$ In addition, hydrogen stabilizes strain-induced vacancies and enhances the formation of lattice defects (vacancies) in metal, which results in mature fracture. This is referred to as the hydrogen-enhanced strain-induced vacancy (HESIV) model. ${ }^{[6-8]}$

Intergranular, ${ }^{[9,10]}$ quasi-cleavage ${ }^{[11-13]}$ and shallow dimple ${ }^{[7,14]}$ fracture modes have been reported as typical fracture surfaces related to HE. Intergranular and quasi-cleavage fracture modes have often been observed in high-strength martensitic steel. ${ }^{[9-12]}$ Close observation beneath the quasi-cleavage fracture surface revealed that local plastic deformation is related to this type of fracture. ${ }^{[12]}$ However, the relationship between the final fracture mode and the embrittlement process occurring at the atomic order level is not clearly understood.

Thermal desorption spectroscopy (TDS) has been applied to determine the kinds and quantities of lattice defects using hydrogen as a probe, i.e., tracer hydrogen. ${ }^{[6,11,15]}$ This method uses the property that hydrogen is trapped at lattice defects in metal. When tracer hydrogen is charged into metals under identical charging 
conditions, it is trapped at various lattice defects depending on their densities and binding energies. Thus, the amount of tracer hydrogen and tracer hydrogen desorption temperatures measured using TDS correlate with the quantity of trapping sites such as lattice defects and the binding energies between hydrogen and trapping sites, respectively.

One of the authors previously reported that tempered martensitic steel showing quasi-cleavage fracture under constant stress in the presence of hydrogen had a larger amount of tracer hydrogen and higher-temperature desorption in the range of the hydrogen desorption spectra than that without hydrogen. ${ }^{[1]}$ The difference in the amounts of tracer hydrogen in steels stressed with and without hydrogen is defined as the amount of hydrogen-enhanced lattice defects. These lattice defects caused ductility loss in a subsequent tensile test even though absorbed hydrogen was not present in the tempered martensitic steel specimen. ${ }^{[1]}$ These results provide direct evidence that the formation of new hydrogen-enhanced lattice defects is one of the main factors of $\mathrm{HE}$ in the case of quasi-cleavage fracture. However, the kinds of hydrogen-enhanced lattice defects and their formation process in the local region near the fracture surface are not well recognized.

For specimens heated from room temperature, it is difficult to identify on the basis of TDS measurements the kinds of lattice defects that form in tempered martensitic steel in the presence of hydrogen and to evaluate their quantities present in the local region near the fracture surface. This is attributed to two restrictions on hydrogen desorption measurement. Firstly, only one hydrogen desorbed peak from thick specimens is obtained due to the diffusion-controlled, rather than the detrap-controlled process, although hydrogen desorbs from various lattice defects. The other is that hydrogen desorbs from thin specimens before the measurement due to the high diffusivity of the body-centered-cubic lattice at room temperature.

Thermal desorption spectroscopy from a low temperature (L-TDS), which can detect hydrogen from a low temperature of $73 \mathrm{~K}$, has been developed to identify hydrogen desorption peaks corresponding to each trapping site in pure iron. ${ }^{[16]}$ For tempered martensitic steels, this L-TDS technique might make it possible to separate and identify the hydrogen peaks of hydrogen-enhanced lattice defects from among various peaks. The presence of hydrogen and the accumulation of strain are important factors in the formation of hydrogen-enhanced lattice defects. In some reports, the effects of the amount of diffusible hydrogen ${ }^{[17]}$ and strain ${ }^{[15]}$ on such defect formation were studied based on the difference in the amount of tracer hydrogen with and without hydrogen using thermal desorption analysis (TDA). However, there are few reports on the separate effects of the amount of diffusible hydrogen and strain on the formation process of hydrogen-enhanced lattice defects based on separation of their hydrogen desorption behavior. Therefore, the conditions for promoting the formation of hydrogen-enhanced lattice defects are still unclear.
Positron annihilation spectroscopy (PAS) is an effective method for detecting vacancy-type defects below nano-order level in metals. ${ }^{[18,19]}$ This technique enables prediction of the size of vacancy-type defects and their relative amounts by measuring the positron lifetime, which is time difference between the time of positron injection into a metal to the time of pair annihilation with an electron. There are reports that plastic straining in the presence of hydrogen formed excess vacancy-type defects compared with the thermal equilibrium amount for pure iron ${ }^{[20]}$ and austenitic stainless steel. ${ }^{[21]}$ However, it is not well known whether vacancy-type defects are formed near the fracture surface in tempered martensitic steel showing the quasi-cleavage fracture mode. PAS has the capability for clarifying this question.

In the present study, an attempt was made using L-TDS to separate the hydrogen peaks corresponding to hydrogen-enhanced lattice defects from various trapping sites in tempered martensitic steel showing quasi-cleavage fracture. The conditions for forming hydrogen-enhanced lattice defects were examined using L-TDS and the kinds of defects were also examined using PAS measurement. An attempt was also made to understand the mechanism causing quasi-cleavage fracture resulting from $\mathrm{HE}$ by clarifying the accumulation process of hydrogen-enhanced lattice defects until final fracture.

\section{PROCEDURE}

\section{A. Material Preparation}

The chemical composition of the steel prepared in the present study was 0.31 mass pet $\mathrm{C}, 1.64$ mass pet $\mathrm{Si}$, and 0.75 mass pet $\mathrm{Mn}$. It was induction-quenched at $1296 \mathrm{~K}$ and tempered at $743 \mathrm{~K}$, resulting in a tempered martensitic structure with tensile strength of $1474 \mathrm{MPa}$. The specimens were round bars of $7.2 \mathrm{~mm}$ in diameter and $150 \mathrm{~mm}$ in gage length.

\section{B. Hydrogen Pre-charging and Hydrogen Analysis}

A center region of $30 \mathrm{~mm}$ in gage length was pre-charged with hydrogen by cathodic electrolysis at a current density of $100 \mathrm{~A} \mathrm{~m}^{-2}$ in a $0.1 \mathrm{~N} \mathrm{NaOH}$ aqueous solution kept at $303 \mathrm{~K}$. To evaluate the effect of the amount of hydrogen on the formation of strain-induced lattice defects, $\mathrm{NH}_{4} \mathrm{SCN}$ of 1.0 or $5.0 \mathrm{~g} \mathrm{~L}^{-1}$ was added to the solution. The amount of hydrogen was analyzed by TDA using a gas chromatograph at a heating rate of $100 \mathrm{~K} \mathrm{~h}^{-1}$ in the temperature range from room temperature to $573 \mathrm{~K}$. A pre-charging time of $96 \mathrm{~h}$ was determined for reaching an equilibrium hydrogen concentration at both the surface and center of the specimens. These pre-charging conditions provided equilibrium hydrogen concentrations of 0.5 and 4.0 mass ppm, respectively, and these two specimens are denoted as $[0.5 \mathrm{H}]$ and $[4.0 \mathrm{H}]$ specimens. The notation $[0 \mathrm{H}]$ denotes a non-hydrogen-charged specimen as a reference specimen. 


\section{Applying Elastic/Plastic Strain}

Elastic and plastic strains were induced in tensile tests at a strain rate of $3.0 \times 10^{-6} \mathrm{~s}^{-1}$. Hydrogen charging was conducted concurrently during the tensile tests under identical pre-charging conditions to prevent hydrogen evolution. For the following four purposes, the strain level conditions were varied.

(1) Separation of hydrogen desorption corresponding to hydrogen-enhanced lattice defects.

(2) Identification of the kind of hydrogen-enhanced lattice defects.

(3) Evaluation of the effect of the straining level and the initial amount of hydrogen on the formation of hydrogen-enhanced lattice defects.

(4) Evaluation of the amount of formed hydrogen-enhanced lattice defects at the final fracture stage.

The notations $\left[0.5 \mathrm{H}+0\right.$ pct $\left.\varepsilon_{\mathrm{p}}\right],\left[0.5 \mathrm{H}+1.3\right.$ pct $\left.\varepsilon_{\mathrm{p}}\right]$, and $\left[0.5 \mathrm{H}+3.3\right.$ pct $\left.\varepsilon_{\mathrm{p}}\right]$ denote $[0.5 \mathrm{H}]$ specimens plastically strained by $0,1.3$, and 3.3 pct, respectively. The $\left[0.5 \mathrm{H}+0\right.$ pct $\left.\varepsilon_{\mathrm{p}}\right]$ specimen was elastically strained by proof stress on stress-displacement curves of the $[0.5 \mathrm{H}]$ specimen. The notation $\left[4.0 \mathrm{H}+1.3\right.$ pct $\left.\varepsilon_{\mathrm{p}}\right]$ denotes a $[4.0 \mathrm{H}]$ specimen plastically strained by 1.3 pct. In addition, the notation $\left[0 \mathrm{H}+3.3\right.$ pct $\left.\varepsilon_{\mathrm{p}}\right]$ denotes a $[0 \mathrm{H}]$ specimen plastically strained by $3.3 \mathrm{pct}$ in air as a reference specimen.

To examine point (1) above, $\left[0 \mathrm{H}+3.3\right.$ pct $\left.\varepsilon_{\mathrm{p}}\right]$ and $[0.5$ $\mathrm{H}+3.3$ pct $\left.\varepsilon_{\mathrm{p}}\right]$ specimens were prepared to separate the formation of strain-induced lattice defects in the absence or presence of hydrogen. In addition, $\left[0.5 \mathrm{H}+3.3 \mathrm{pct} \varepsilon_{\mathrm{p}}\right]$ specimens were cut from various positions distant from the fracture surface for investigating points (2) and (4). For examining point (3), $\left[0.5 \mathrm{H}+0\right.$ pct $\left.\varepsilon_{\mathrm{p}}\right], \quad[0.5$ $\mathrm{H}+1.3$ pct $\left.\varepsilon_{\mathrm{p}}\right]$, and $\left[0.5 \mathrm{H}+3.3\right.$ pct $\left.\varepsilon_{\mathrm{p}}\right]$ specimens were prepared for clarifying the effect of plastic straining. [0.5 $\mathrm{H}+1.3$ pct $\left.\varepsilon_{\mathrm{p}}\right]$ and $\left[4.0 \mathrm{H}+1.3\right.$ pct $\left.\varepsilon_{\mathrm{p}}\right]$ specimens were prepared to reveal the effect of the amount of hydrogen. The specimens were machined to a disk shape of $7.2 \mathrm{~mm}$ in diameter and less than $2 \mathrm{~mm}$ in thickness. Fractured $\left[0.5 \mathrm{H}+3.3\right.$ pct $\left.\varepsilon_{\mathrm{p}}\right]$ and $\left[4.0 \mathrm{H}+1.3\right.$ pct $\left.\varepsilon_{\mathrm{p}}\right]$ specimens were cut from the vicinity of the fracture surface and other unfractured specimens were cut from the 30-mm-long center region.

\section{Tracer Hydrogen Charging and L-TDS Measurement}

The specimens were charged with tracer hydrogen under identical charging conditions in order to use hydrogen as a probe for determining the kinds of lattice defects present and their quantities. Disk-shaped specimens were mechanically polished and chemically etched in a solution of $\mathrm{H}_{2} \mathrm{O}_{2}$ and $\mathrm{H}_{3} \mathrm{PO}_{4}$, which reduced their thickness by $0.2 \mathrm{~mm}$. Pre-charged hydrogen was degassed at room temperature for $48 \mathrm{~h}$. No residual hydrogen was observed by TDA after hydrogen degassing for $48 \mathrm{~h}$. Tracer hydrogen was then charged to the specimens by immersing them in an aqueous solution of 0.05 mass pet $\mathrm{NH}_{4} \mathrm{SCN}$ for $24 \mathrm{~h}$ to reach an equilibrium hydrogen concentration at both their surface and center.
For investigating point (4), tracer hydrogen was charged by cathodic electrolysis at a current density of $100 \mathrm{~A} \mathrm{~m}^{-2}$ in a $0.1 \mathrm{~N} \mathrm{NaOH}$ aqueous solution kept at $303 \mathrm{~K}$ instead of by immersion in the $\mathrm{NH}_{4} \mathrm{SCN}$ solution to prevent the specimens from corroding. After tracer hydrogen charging, the specimens were kept in liquid nitrogen to prevent hydrogen evolution and subsequently hydrogen analysis was carried out by L-TDS at a heating rate of $1 \mathrm{~K} \mathrm{~min}^{-1}$ in a temperature range from $73 \mathrm{~K}$ to $473 \mathrm{~K}$.

\section{E. Positron Annihilation Spectroscopy (PAS)}

The positron source for PAS was a $0.5 \mathrm{MBq}$ positron source of ${ }^{22} \mathrm{Na}$ sealed with Kapton films of $7.5 \mu \mathrm{m}$ in thickness (Na351 supplied by the Japan Radioisotope Association). The $[0 \mathrm{H}], \quad\left[0 \mathrm{H}+3.3 \mathrm{pct} \varepsilon_{\mathrm{p}}\right]$, and $\left[0.5 \mathrm{H}+3.3\right.$ pct $\left.\varepsilon_{\mathrm{p}}\right]$ specimens were polished mechanically and then immersed in the chemical etching solution to remove the work hardening layer on the surface. The source was placed between two specimens. The lifetime of every positron was measured as a time interval between a $\gamma$-ray of $1.27 \mathrm{MeV}$ emitted from ${ }^{22} \mathrm{Na}$ almost simultaneously with the positron injection into the specimens and one of annihilation, $511 \mathrm{keV} \gamma$-rays, that was calculated based on the time at which the $1.27 \mathrm{MeV}$ and $511 \mathrm{keV}$ pulses observed by a storage digital oscilloscope (Wavepro 7100A, LeCroy) crossed the constant fraction of 25 pct of the amplitudes. ${ }^{[22]}$ Each positron lifetime spectrum consisted of more than $10^{6}$ counts. The time resolution was about 160 ps (FWHM). Positron lifetime spectra were analyzed using the PALSfit program. ${ }^{[23]}$

\section{RESULTS}

\section{A. Mechanical Degradation and Fracture Morphology Caused by $H E$}

Stress-displacement curves obtained in tensile testing of the $[0 \mathrm{H}],[0.5 \mathrm{H}]$, and $[4.0 \mathrm{H}]$ specimens at an initial strain rate of $3.0 \times 10^{-6} \mathrm{~s}^{-1}$ are shown in Figure 1. The mechanical properties in the tensile tests conducted with/without hydrogen charging are listed in Table I. Proof strength did not significantly change between the absence or presence of hydrogen, while tensile strength and elongation decreased with an increasing amount of initial hydrogen. SEM images of the fracture surfaces near the fracture origin for the (a) $[0 \mathrm{H}],(b)[0.5 \mathrm{H}]$, and (c) $\left[\begin{array}{ll}4.0 & \mathrm{H}\end{array}\right]$ specimens are shown in Figure 2. The fracture origin of the $[0 \mathrm{H}]$ specimen shows dimples typical of ductile fracture. In contrast, the fracture origins of both the $[0.5 \mathrm{H}]$ and $[4.0 \mathrm{H}]$ specimens exhibit typical quasi-cleavage fracture.

\section{B. Tracer Hydrogen Desorption from Hydrogen-Enhanced Lattice Defects}

Tracer hydrogen desorption spectra and the amounts of tracer hydrogen desorbed from the $\left[\begin{array}{ll}0 & H\end{array}\right]$, $\left[0 \mathrm{H}+3.3\right.$ pct $\left.\varepsilon_{\mathrm{p}}\right]$, and $\left[0.5 \mathrm{H}+3.3\right.$ pct $\left.\varepsilon_{\mathrm{p}}\right]$ specimens 
measured by L-TDS are shown in Figure 3. For the $\left[\begin{array}{ll}0 & \mathrm{H}\end{array}\right]$ specimen, the tracer hydrogen desorption spectrum had a single peak; hydrogen first desorbed at $223 \mathrm{~K}$, maximally desorbed at $273 \mathrm{~K}$ and disappeared at $343 \mathrm{~K}$. In the case of the $\left[0 \mathrm{H}+3.3 \mathrm{pct} \varepsilon_{\mathrm{p}}\right]$ specimen, the tracer hydrogen desorption spectrum consisted of a large peak and a slight shoulder in the temperature range from $223 \mathrm{~K}$ to $463 \mathrm{~K}$. The tracer hydrogen desorption spectrum of the $\left[0.5 \mathrm{H}+3.3\right.$ pct $\left.\varepsilon_{\mathrm{p}}\right]$ specimen

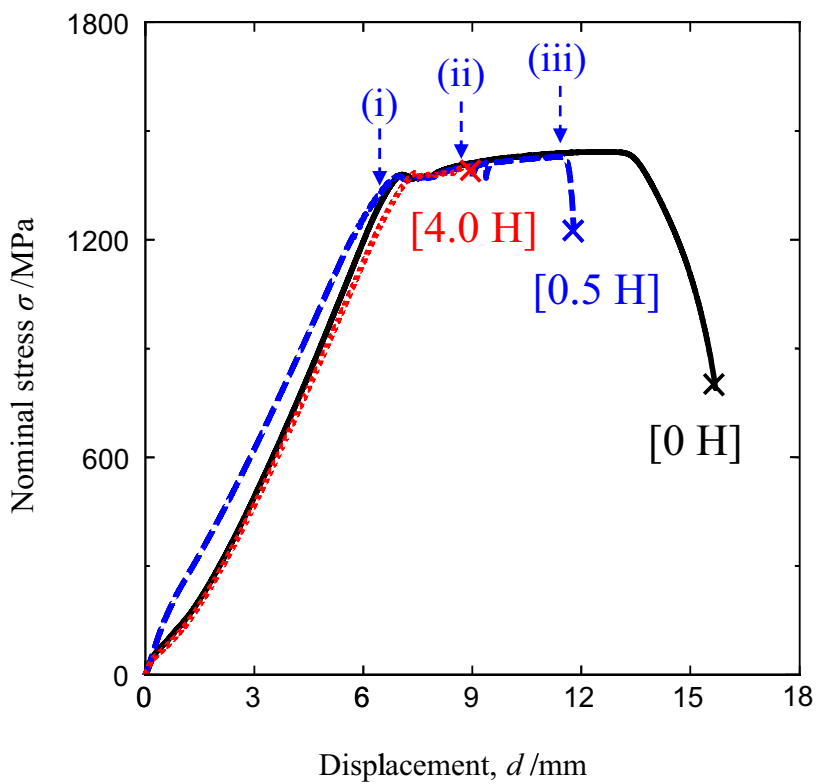

Fig. 1-Stress-displacement curves of tempered martensitic steel specimens containing the amount of hydrogen of $0,0.5$, and 4.0 mass ppm. Three arrows of (i), (ii), and (iii) show application points of various plastic strains of $0,1.3$, and 3.3 pct, respectively. consisted of two distinct peaks at $293 \mathrm{~K}$ and $371 \mathrm{~K}$. The amount of tracer hydrogen increased from $0.07 \mathrm{ppm}$ for the $[0 \mathrm{H}]$ specimen to $0.20 \mathrm{ppm}$ for the $\left[0 \mathrm{H}+3.3 \mathrm{pct} \varepsilon_{\mathrm{p}}\right]$ specimen. The amount of tracer hydrogen desorbed from the $\left[0.5 \mathrm{H}+3.3 \mathrm{pct} \varepsilon_{\mathrm{p}}\right]$ specimen increased further to $0.32 \mathrm{ppm}$.

A comparison of tracer hydrogen desorption spectra between the experimental data and curves fitted with the Gaussian function for the $\left[0 \mathrm{H}+3.3 \mathrm{pct} \varepsilon_{\mathrm{p}}\right]$ and $[0.5$ $\mathrm{H}+3.3$ pct $\left.\varepsilon_{\mathrm{p}}\right]$ specimens is shown in Figures 4(a) and (b),

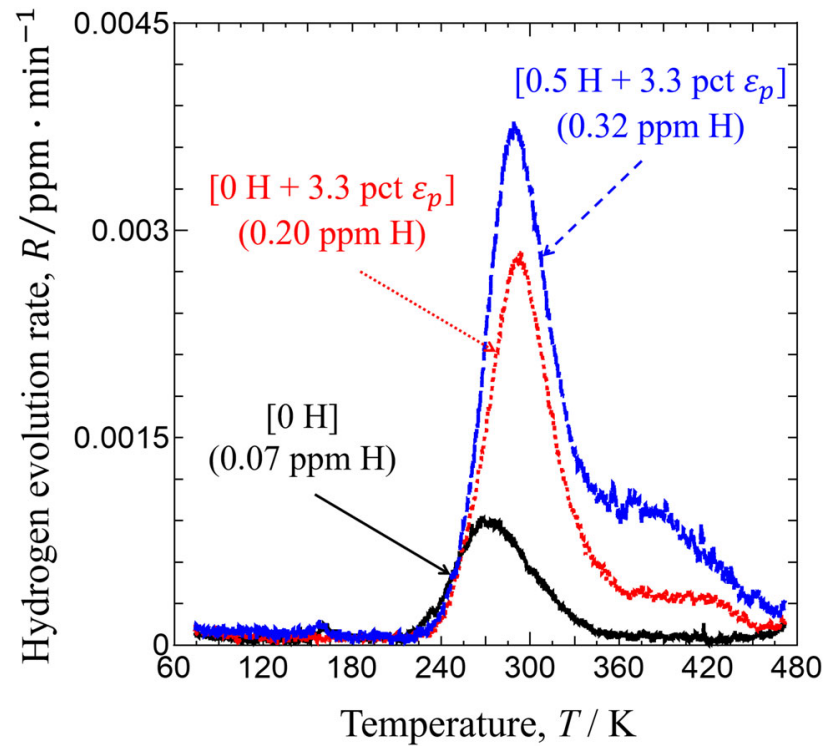

Fig. 3-Tracer hydrogen desorption spectra and the amount of tracer hydrogen corresponding to the amounts of lattice defects of $[0 \mathrm{H}],\left[0 \mathrm{H}+3.3\right.$ pct $\left.\varepsilon_{\mathrm{p}}\right]$, and $\left[0.5 \mathrm{H}+3.3\right.$ pct $\left.\varepsilon_{\mathrm{p}}\right]$ specimens.

Table I. Mechanical Properties of Tempered Martensite Containing 0, 0.5, and 4.0 Mass ppm Hydrogen

\begin{tabular}{lcccc}
\hline Specimens & Initial Amount of $H($ mass ppm) & Proof Stress $(\mathrm{MPa})$ & Tensile Strength $(\mathrm{MPa})$ & Elongation $(\mathrm{Pct})$ \\
\hline$[0 \mathrm{H}]$ & 0 & 1380 & 1442 & 7.7 \\
{$[0.5 \mathrm{H}]$} & 0.5 & 1377 & 1428 & 4.1 \\
{$[4.0 \mathrm{H}]$} & 4.0 & 1386 & 1402 & 1.3 \\
\hline
\end{tabular}

*Elongation was calculated from displacement after removing displacement of elastic deformation. Gage length:150 mm.

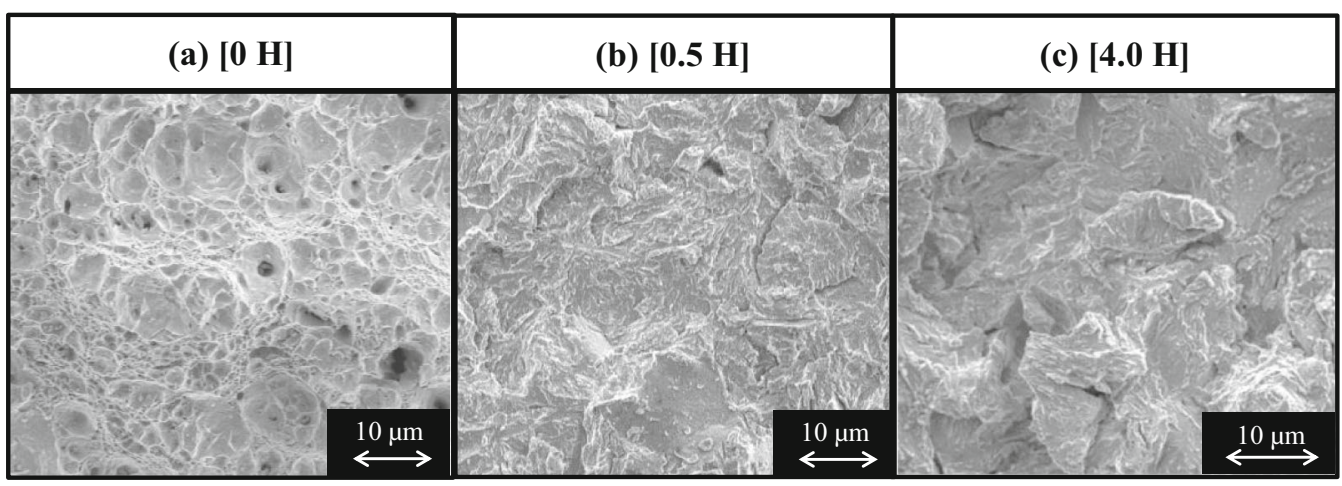

Fig. 2-Scanning electron micrographs of the fracture surfaces of $(a)[0 \mathrm{H}],(b)[0.5 \mathrm{H}]$, and $(c)[4.0 \mathrm{H}]$ specimens. 


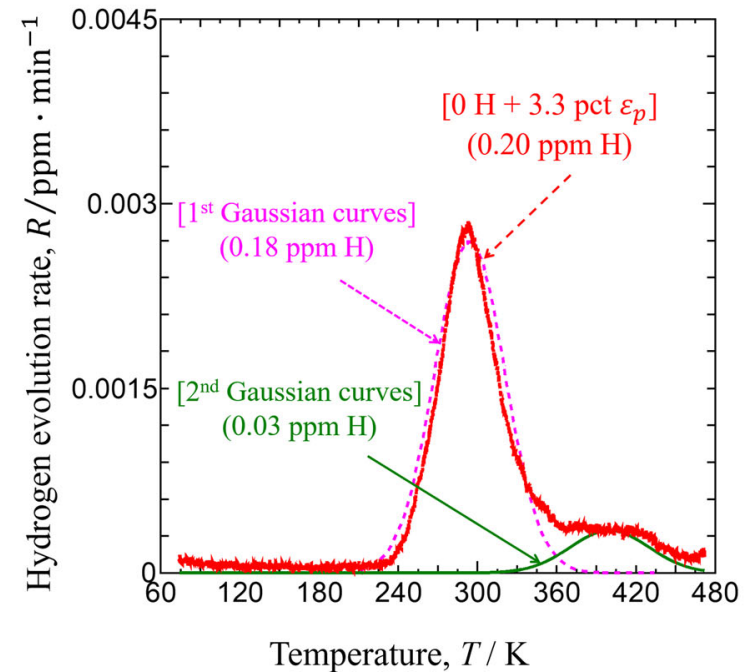

(a)

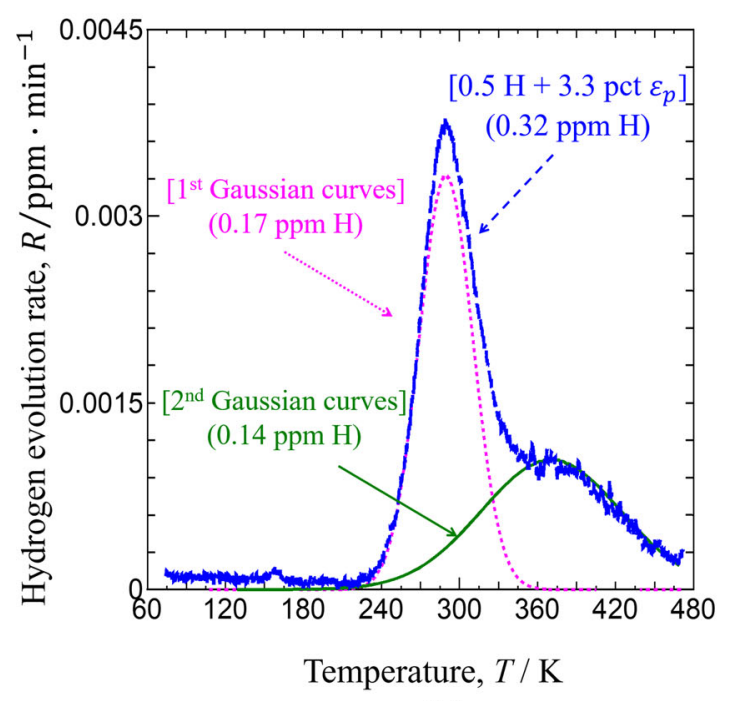

(b)

Fig. 4 - Comparison of hydrogen desorption spectra between experiment and fitting using Gaussian function: $(a)\left[0 \mathrm{H}+3.3\right.$ pct $\left.\varepsilon_{\mathrm{p}}\right]$ specimen, $(b)$ $\left[0.5 \mathrm{H}+3.3\right.$ pct $\left.\varepsilon_{\mathrm{p}}\right]$ specimen.

respectively. Two distinct peaks denoted as the 1st and 2nd Gaussian curves are observed at peak temperatures of 293 and $371 \mathrm{~K}$, respectively. For the 1st Gaussian curve of the $\left[0.5 \mathrm{H}+3.3\right.$ pet $\left.\varepsilon_{\mathrm{p}}\right]$ specimen as shown in Figure 4(b), tracer hydrogen desorbed in the temperature range from $223 \mathrm{~K}$ to $343 \mathrm{~K}$ with a peak temperature of $293 \mathrm{~K}$. In contrast, for the 2nd Gaussian curve, tracer hydrogen desorbed broadly in the temperature range from $223 \mathrm{~K}$ to $473 \mathrm{~K}$ with a peak temperature of $371 \mathrm{~K}$. The Gaussian function for the [0 $\mathrm{H}+3.3$ pct $\varepsilon_{\mathrm{p}}$ ] specimen in Figure 4(a) was also decomposed into two peaks: the 1st Gaussian curve was distinct, while the 2nd Gaussian curve was slight. Notably, the amount of tracer hydrogen of the 1st Gaussian curve of the $\left[0 \mathrm{H}+3.3\right.$ pct $\left.\varepsilon_{\mathrm{p}}\right]$ and $\left[0.5 \mathrm{H}+3.3\right.$ pct $\left.\varepsilon_{\mathrm{p}}\right]$ specimens was 0.18 and $0.17 \mathrm{ppm}$, respectively. These results indicate that the density of hydrogen trapping sites corresponding to the 1st Gaussian curve was approximately equal. Since the hydrogen desorption temperature measured by L-TDS corresponds to the binding energy between hydrogen and trapping sites, the two hydrogen desorption peaks from both the $\left[0 \mathrm{H}+3.3\right.$ pct $\left.\varepsilon_{\mathrm{p}}\right]$ and $\left[0.5 \mathrm{H}+3.3\right.$ pct $\left.\varepsilon_{\mathrm{p}}\right]$ specimens were probably desorption from two different kinds of lattice defects.

Therefore, the L-TDS results clearly indicate that plastic straining induced two kinds of lattice defects and the presence of hydrogen markedly increased the amount of hydrogen desorption from lattice defects corresponding to the 2nd Gaussian curve.

\section{Effect of Amounts of Plastic Straining and Initial Hydrogen on the Formation of Hydrogen-Enhanced Lattice Defects}

First, the effect of the amount of applied plastic strain in the presence of hydrogen on the formation of lattice defects was studied. Hydrogen desorption spectra and the amounts of tracer hydrogen desorbed from the $[0.5 \mathrm{H}]$ specimens subjected to various levels of plastic strain under an identical initial amount of hydrogen of $0.5 \mathrm{ppm}$ measured using L-TDS are shown in Figure 5(a). The levels of plastic strain applied were (i) 0 pct $\varepsilon_{\mathrm{p}}$, (ii) 1.3 pct $\varepsilon_{\mathrm{p}}$, and (iii) 3.3 pct $\varepsilon_{\mathrm{p}}$ shown on the stress-displacement curves as arrows in Figure 1. The tracer hydrogen desorbed from the $\left[0.5 \mathrm{H}+0\right.$ pet $\left.\varepsilon_{\mathrm{p}}\right]$ specimen had a single peak at $273 \mathrm{~K}$, while the tracer hydrogen desorbed from the $\left[0.5 \mathrm{H}+1.3\right.$ pct $\left.\varepsilon_{\mathrm{p}}\right]$ specimen showed a distinct peak at $293 \mathrm{~K}$ and a slight peak at $373 \mathrm{~K}$. For the $[0.5$ $\mathrm{H}+3.3$ pct $\left.\varepsilon_{\mathrm{p}}\right]$ specimen, tracer hydrogen desorption increased markedly at peak temperatures of $293 \mathrm{~K}$ and $371 \mathrm{~K}$. The amount of lattice defects corresponding to desorption at around $371 \mathrm{~K}$ increased slightly in the strain range of uniform elongation, i.e., 1.3 pet plastic strain, whereas it increased dramatically at the plastic strain level of final fracture, i.e., 3.3 pct plastic strain.

Second, the effect of the initial amount of hydrogen during plastic straining on the formation of lattice defects was also investigated. Hydrogen desorption spectra and the amounts of tracer hydrogen measured by L-TDS for the $\left[0.5 \mathrm{H}+1.3 \mathrm{pct} \varepsilon_{\mathrm{p}}\right]$ and $[4.0$ $\mathrm{H}+1.3$ pct $\left.\varepsilon_{\mathrm{p}}\right]$ specimens subjected to an identical plastic strain of 1.3 pct are shown in Figure 5(b). The $\left[\begin{array}{lll}4.0 & \mathrm{H} \\ & +1.3 \mathrm{pct} & \varepsilon_{\mathrm{p}}\end{array}\right]$ specimen desorbed a larger amount of tracer hydrogen than the $[0.5 \mathrm{H}+1.3 \mathrm{pct}$ $\left.\varepsilon_{\mathrm{p}}\right]$ specimen; however, it desorbed much less tracer hydrogen than the $\left[0.5 \mathrm{H}+3.3\right.$ pct $\left.\varepsilon_{\mathrm{p}}\right]$ specimen in Figure 5(a). It is inferred that the amount of plastic straining in the presence of hydrogen had a greater effect on the formation of lattice defects than the initial amount of hydrogen.

\section{Distribution of Hydrogen-Enhanced Lattice Defects at the Final Fracture Stage}

Tracer hydrogen desorption spectra and the distribution of the amount of tracer hydrogen of the $[0.5$ $\mathrm{H}+3.3$ pct $\left.\varepsilon_{\mathrm{p}}\right]$ specimens cut at different distances from 




(a)

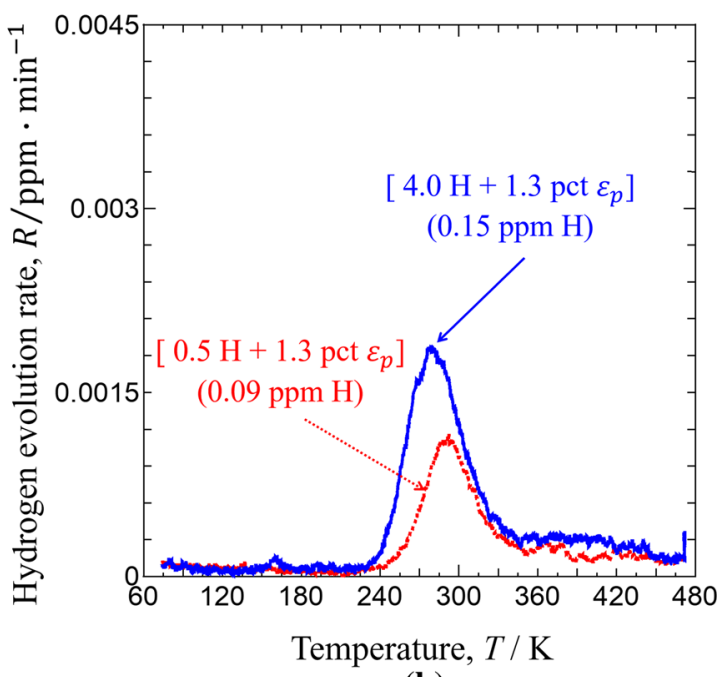

(b)

Fig. 5-Hydrogen desorption spectra and the amount of tracer hydrogen corresponding to the amounts of lattice defects of $[0.5 \mathrm{H}+1.3 \mathrm{pct}$ $\left.\varepsilon_{\mathrm{p}}\right]$ and $\left[4.0 \mathrm{H}+1.3 \mathrm{pct} \varepsilon_{\mathrm{p}}\right]$ specimens; $(a)$ an effect of plastic strain on tracer hydrogen desorption spectra and the amount of tracer hydrogen of specimens containing initial hydrogen of 0.5 mass ppm and $(b)$ an effect of the initial amount of hydrogen on tracer hydrogen desorption spectra and the amount of tracer hydrogen of specimens subjected to plastic strain of 1.3 pct.

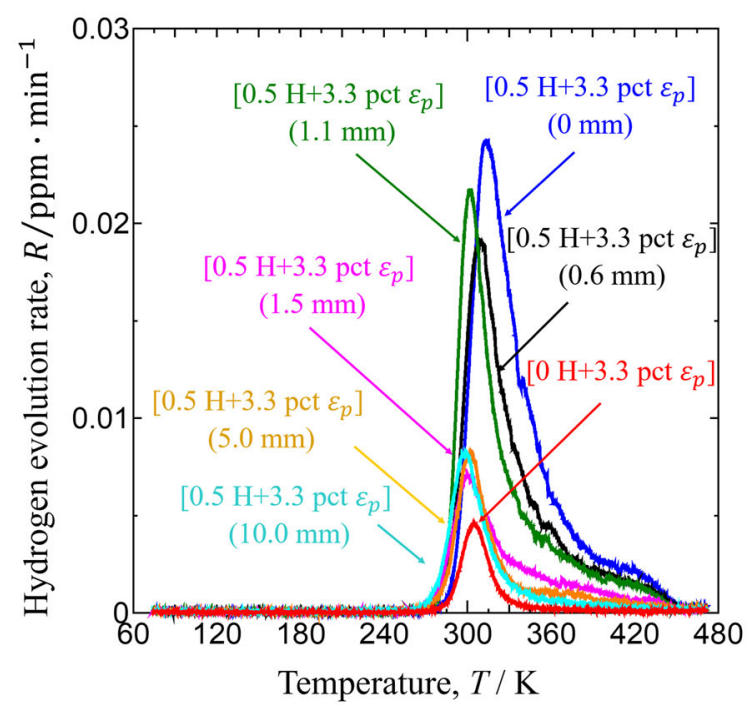

(a)

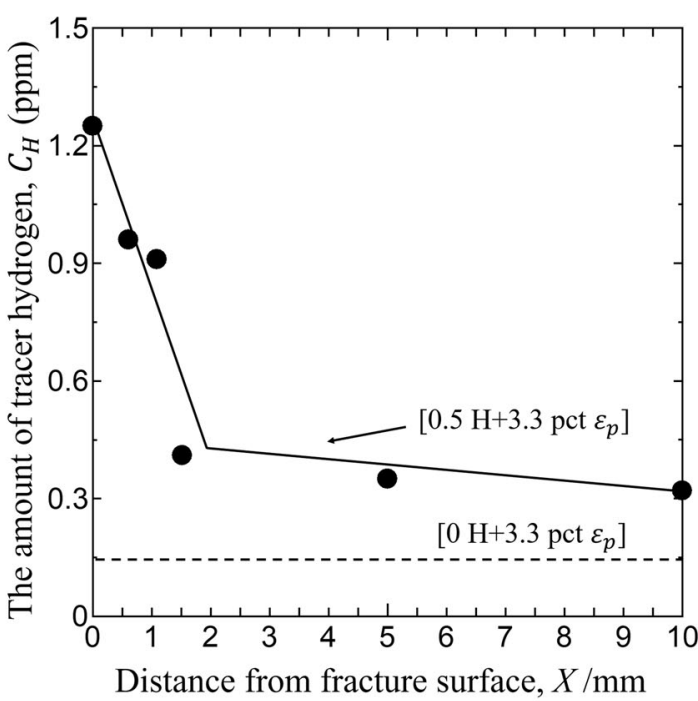

(b)

Fig. 6- (a) Hydrogen desorption spectra and (b) the amount of tracer hydrogen of the $\left[0.5 \mathrm{H}+3.3\right.$ pct $\left.\varepsilon_{\mathrm{p}}\right]$ specimens cut at various distances from the fracture surface. The $\left[0 \mathrm{H}+3.3 \mathrm{pct} \varepsilon_{\mathrm{p}}\right]$ specimen was cut from the center of the 30 -mm-long center region, and the hydrogen content is shown by the dashed line as a reference value.

the fracture surface are shown in Figures 6(a) and (b), respectively. That of the $\left[0 \mathrm{H}+3.3\right.$ pet $\left.\varepsilon_{\mathrm{p}}\right]$ specimen was measured by using a specimen cut from 30 -mm-long region. The amount of tracer hydrogen desorption of the $\left[0.5 \mathrm{H}+3.3\right.$ pct $\left.\varepsilon_{\mathrm{p}}\right]$ specimens was more than that of the $\left[0 \mathrm{H}+3.3\right.$ pct $\left.\varepsilon_{\mathrm{p}}\right]$ specimen over the region $10-\mathrm{mm}$ distant from the fracture surface. Notably, the amount of tracer hydrogen desorption of the $\left[0.5 \mathrm{H}+3.3\right.$ pct $\left.\varepsilon_{\mathrm{p}}\right]$ specimens within a $1.5-\mathrm{mm}$ region from the fracture surface significantly increased compared with the more distant region. This distribution result is direct evidence that hydrogen-enhanced lattice defects accumulated locally just prior to final fracture, resulting in quasi-cleavage fracture. In addition, the prominent increase in tracer hydrogen desorption of the $[0.5$ $\mathrm{H}+3.3$ pct $\left.\varepsilon_{\mathrm{p}}\right]$ specimens beneath the fracture surface was observed in the temperature range from $240 \mathrm{~K}$ to $473 \mathrm{~K}$.

\section{E. Positron Annihilation Spectroscopy}

Positron annihilation spectra of the $\left[\begin{array}{ll}0 & \mathrm{H}\end{array}\right],[0$ $\mathrm{H}+3.3$ pct $\left.\varepsilon_{\mathrm{p}}\right]$, and $\left[0.5 \mathrm{H}+3.3\right.$ pct $\left.\varepsilon_{\mathrm{p}}\right]$ specimens obtained by PAS are shown in Figure 7(a). The 
components of both positron annihilation in Kapton and background caused by random coincident were subtracted from the obtained spectra and then the spectra were normalized to the maximum positron annihilation counts. PAS measurement for three [0.5 $\mathrm{H}+3.3$ pct $\left.\varepsilon_{\mathrm{p}}\right]$ specimens was performed and, although no dominant difference was recognized on the three spectra, the spectrum giving the minimum mean positron lifetime is shown in Figure 7(a). The spectrum of the $\left[0 \mathrm{H}+3.3 \mathrm{pct} \varepsilon_{\mathrm{p}}\right]$ specimen showed a longer positron lifetime than the $[0 \mathrm{H}]$ specimen. In addition, a longer positron lifetime was detected for the $[0.5$ $\mathrm{H}+3.3$ pct $\left.\varepsilon_{\mathrm{p}}\right]$ specimen compared with that of the $[0$ $\mathrm{H}+3.3$ pct $\left.\varepsilon_{\mathrm{p}}\right]$ specimen. The L-TDS results imply that the $\left[0 \mathrm{H}+3.3\right.$ pet $\left.\varepsilon_{\mathrm{p}}\right]$ and $\left[0.5 \mathrm{H}+3.3\right.$ pct $\left.\varepsilon_{\mathrm{p}}\right]$ specimens contained two kinds of strain-induced lattice defects.

Positron annihilation spectra measured by PAS for the $[0 \mathrm{H}],\left[0 \mathrm{H}+3.3\right.$ pct $\left.\varepsilon_{\mathrm{p}}\right]$, and $\left[0.5 \mathrm{H}+3.3\right.$ pct $\left.\varepsilon_{\mathrm{p}}\right]$ specimens were analyzed by three exponential decay components and their mean positron lifetimes are shown in Figure $7(\mathrm{~b})$. The mean positron lifetime $\left(\varepsilon_{\mathrm{p}}\right)$ of the $[0 \mathrm{H}]$, and $\left[0 \mathrm{H}+3.3\right.$ pct $\left.\varepsilon_{\mathrm{p}}\right]$ specimens was 140 and $160 \mathrm{ps}$, respectively, and $\tau_{\mathrm{m}}$ for three $\left[0.5 \mathrm{H}+3.3\right.$ pct $\left.\varepsilon_{\mathrm{p}}\right]$ specimens was 165, 167, and 169 ps.

\section{DISCUSSION}

In this study, (A) the kind, (B) the promotion condition of the formation, and (C) the accumulation behavior until final fracture of hydrogen-enhanced lattice defects formed in hydrogen-embrittled tempered martensitic steel showing quasi-cleavage fracture were analyzed comprehensively by L-TDS and PAS. The formation mechanism of hydrogen-enhanced lattice defects is discussed here first based on the present results in the context of the literature. The mechanism by which these lattice defects cause quasi-cleavage fracture is then discussed.

\section{A. Identification of the Kind of Hydrogen-Enhanced Lattice Defects}

As shown in Figure 3, tracer hydrogen desorption of the $\left[0 \mathrm{H}+3.3\right.$ pct $\left.\varepsilon_{\mathrm{p}}\right]$ and $\left[0.5 \mathrm{H}+3.3\right.$ pct $\left.\varepsilon_{\mathrm{p}}\right]$ specimens increased in two different temperature ranges. A significant increase in hydrogen desorption in the high-temperature range was seen from the $\left[0.5 \mathrm{H}+3.3\right.$ pct $\left.\varepsilon_{\mathrm{p}}\right]$ specimens in Figure 4(b). The kinds of hydrogen trapping sites corresponding to this increase in tracer hydrogen desorption are discussed below. Since the $[0 \mathrm{H}]$ specimen with a tempered martensitic structure originally possessed a high density of dislocations, grain boundaries and carbide precipitations, tracer hydrogen desorbed in the temperature range from $223 \mathrm{~K}$ to $343 \mathrm{~K}$ as shown in Figure 3, corresponding to the hydrogen trapped at these trapping sites. It has been reported that applying plastic strain raises the density of dislocations ${ }^{[24]}$ that can act as hydrogen trapping sites. ${ }^{[25]}$ It is assumed that the increase in the amount of tracer hydrogen seen for the $[0$ $\mathrm{H}+3.3$ pct $\left.\varepsilon_{\mathrm{p}}\right]$ and $\left[0.5 \mathrm{H}+3.3\right.$ pct $\left.\varepsilon_{\mathrm{p}}\right]$ specimens with a peak temperature of $293 \mathrm{~K}$ corresponds to the increase in the density of dislocations. The amounts of tracer hydrogen corresponding to desorption from the disloca-

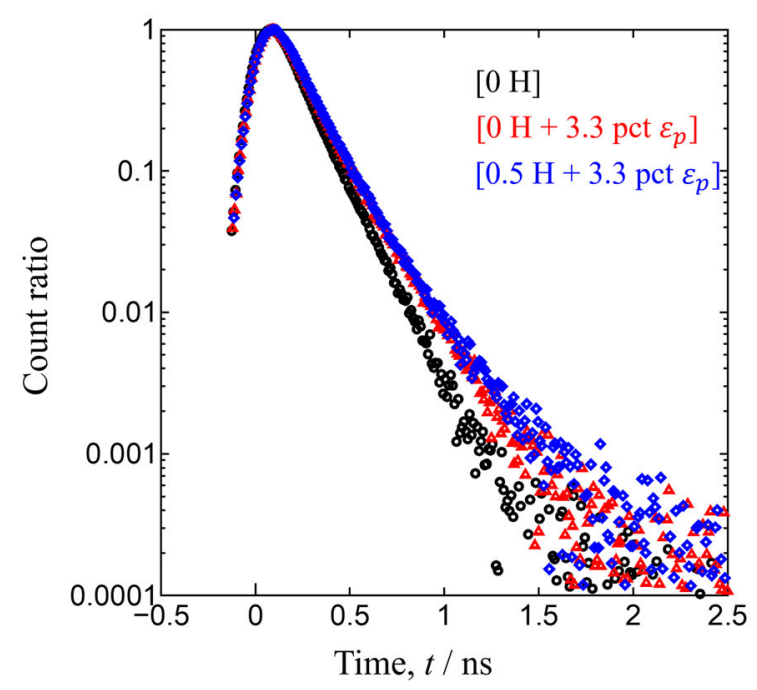

(a)

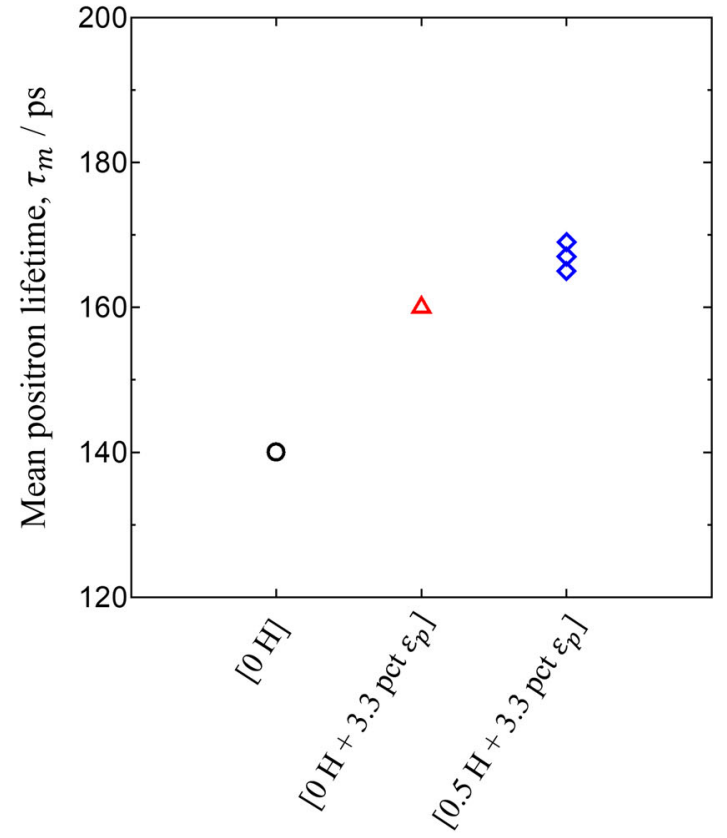

(b)

Fig. 7-(a) Normalized positron lifetime spectra by maximum positron annihilation counts, and $(b)$ mean positron lifetime for [0 H], $\left[0 \mathrm{H}+3.3 \mathrm{pct} \varepsilon_{\mathrm{p}}\right]$, and $\left[0.5 \mathrm{H}+3.3 \mathrm{pct} \varepsilon_{\mathrm{p}}\right]$ specimens. The components of both positron annihilation in Kapton and background caused by random coincident were subtracting from the obtained spectra. 
tions were 0.18 and 0.17 ppm for the $\left[0 \mathrm{H}+3.3\right.$ pct $\left.\varepsilon_{\mathrm{p}}\right]$ specimen and the $\left[0.5 \mathrm{H}+3.3\right.$ pct $\left.\varepsilon_{\mathrm{p}}\right]$ specimen in Figure 4, respectively. This finding revealed that the increase in the density of dislocations formed newly by applying an identical level of plastic strain was approximately equal, whether hydrogen was present or not.

Tracer hydrogen desorption from the $[0.5 \mathrm{H}+3.3 \mathrm{pct}$ $\left.\varepsilon_{\mathrm{p}}\right]$ specimen significantly increased at a peak temperature of $371 \mathrm{~K}$. The hydrogen desorption temperature measured by L-TDS reflects the binding energy between hydrogen and trapping sites or the thermal stability of trapping sites. In the present study, tracer hydrogen desorption corresponding to dislocations displayed a peak temperature of $293 \mathrm{~K}$ and dislocations were thermally stable until $473 \mathrm{~K}$. This increase suggests that applying plastic strain in the presence of hydrogen enhanced the formation of not only dislocations but also other kinds of lattice defects. Furthermore, the 2nd Gaussian curve probably corresponds to hydrogen desorption from multiple hydrogen trapping sites with different binding energies or thermal stabilities since the curve is broadly distributed in the temperature range for tracer hydrogen desorption.

PAS measurement was performed to identify the kinds of lattice defects formed by hydrogen and plastic strain. As show in Figure 7, whether hydrogen was present or not, positron annihilation was detected in a longer positron lifetime more frequently for plastic straining as well as an increase in the mean positron lifetime ( $\tau_{\mathrm{m}}$ of 140 to $160 \mathrm{ps}$ ). In addition, in the presence of hydrogen, positron annihilation in a longer positron lifetime was markedly observed and the mean positron lifetime increased ( $\tau_{\mathrm{m}}$ of 160 to 165 to $169 \mathrm{ps}$ ). The kinds of hydrogen-enhanced lattice defects are discussed below according to the change in the mean positron lifetime in reference to the positron lifetime of bulk and lattice defects (dislocations and vacancy-type defects) in the literature. The mean positron lifetime of the $[0 \mathrm{H}]$ specimen was $140 \mathrm{ps}$. Since the specimens had a martensitic microstructure subjected to induction tempering at $743 \mathrm{~K}$, they presumably contained a high density of dislocations and no vacancy-type defects. Reported positron lifetimes in bulk for iron were $101 \mathrm{ps}^{[26]}$ and $104 \mathrm{ps}^{[27]}$ based on first-principles calculations. It is reported by Hidalgo et al. that the lifetime of positron trapped at dislocations was 150 ps for pure iron. ${ }^{[28]}$ Yoshida et al. also reported that 152 ps was the lifetime of positrons trapped at dislocations for tempered HT780 subjected to cyclically elastic stress. ${ }^{[29]}$

The mean positron lifetime of the $[0 \mathrm{H}]$ specimen was shorter than the reported values for dislocations. ${ }^{[28,29]}$ This means some positrons in the $[0 \mathrm{H}]$ specimens were annihilated in bulk prior to being trapped at dislocations. The increase in $\tau_{\mathrm{m}}$ from $140 \mathrm{ps}$ for the $[0 \mathrm{H}]$ specimen to $160 \mathrm{ps}$ for the $\left[0 \mathrm{H}+3.3\right.$ pct $\left.\varepsilon_{\mathrm{p}}\right]$ specimen presumably corresponds to the increase in the density of lattice defects induced by plastic straining. Therefore, together with the L-TDS results, these findings indicate that plastic straining formed lattice defects with a longer positron lifetime than that of dislocations in the absence of hydrogen.
Many researchers have reported that plastic deformation induces vacancy-types defects in metal. ${ }^{[30]}$ Ohkubo et al. calculated the lifetime of positrons trapped at mono-vacancies as 180 ps. ${ }^{[27]}$ Vehanen et al. reported a positron lifetime of 175 ps for mono-vacancies in electron-irradiated pure iron. ${ }^{[19]}$ In addition, it has been reported that positron lifetimes of clustered vacancies increase with the size of vacancies. ${ }^{[19,27]}$ All things considered, it is assumed that the increase in the mean positron lifetime seen for the $\left[0 \mathrm{H}+3.3\right.$ pct $\left.\varepsilon_{\mathrm{p}}\right]$ specimen corresponds to the increase in the density of dislocations and vacancy-type defects induced in the plastic deformation process. $\tau_{\mathrm{m}}$ increased from $160 \mathrm{ps}$ for the $\left[0 \mathrm{H}+3.3\right.$ pct $\left.\varepsilon_{\mathrm{p}}\right]$ specimen to 165 to 169 ps for the $\left[0.5 \mathrm{H}+3.3\right.$ pct $\left.\varepsilon_{\mathrm{p}}\right]$ specimens. From the L-TDS results, the amount of tracer hydrogen attributed to dislocations did not change whether hydrogen was present or not, and tracer hydrogen desorption in the high-temperature range markedly increased for plastic straining in the presence of hydrogen. Based on the discussion for the $\left[0 \mathrm{H}+3.3\right.$ pct $\left.\varepsilon_{\mathrm{p}}\right]$ specimens, tracer hydrogen desorption in the high-temperature range for these specimens presumably corresponded to vacancytype defects.

As will be discussed later in an analysis of positron lifetime decomposition, the mean positron lifetimes for the $\left[0.5 \mathrm{H}+3.3\right.$ pct $\left.\varepsilon_{\mathrm{p}}\right]$ specimens were longer than that for the $\left[0 \mathrm{H}+3.3\right.$ pct $\left.\varepsilon_{\mathrm{p}}\right]$ specimen, because hydrogen increases the density of initially formed vacancy-type defects, and then agglomeration of the defects makes the cluster size larger. Hence, these results reveal that plastic straining in the presence of hydrogen enhanced the formation of vacancy-type defects. L-TDS enabled separation of hydrogen desorption corresponding to these lattice defects as hydrogen desorption spectra with a peak temperature of approximately $371 \mathrm{~K}$.

The positron lifetimes and their intensity were then analyzed in the following way in order to discuss the quantity of vacancy-type defects formed in the $\left[0 \mathrm{H}+3.3\right.$ pct $\left.\varepsilon_{\mathrm{p}}\right]$ and $\left[0.5 \mathrm{H}+3.3\right.$ pct $\left.\varepsilon_{\mathrm{p}}\right]$ specimens. When multiple sites for positron annihilation exist, the observed $\tau_{\mathrm{m}}$ can be resolved into components with the lifetime $\tau_{i}$,

$$
\tau_{\mathrm{m}}=\sum_{i=1}^{N} I_{\mathrm{i}} \times \tau_{\mathrm{i}},
$$

where $I_{\mathrm{i}}$ represents the ratio of relative intensity of the $\tau_{\mathrm{i}}$ components. ${ }^{[19]}$

Positron annihilation spectra were analyzed by three exponential decay components because positrons annihilate probably in bulk, at dislocations and at vacancy-type defects. $\tau_{2}$ of 157 ps for the $[0 \mathrm{H}]$ specimen is presumably attributed to the lifetime of positrons annihilated at dislocations, because the $[0 \mathrm{H}]$ specimen should have few vacancy-type defects. $157 \mathrm{ps}$ is very close to the reported values of $150 \mathrm{ps}^{[28]}$ and $152 \mathrm{ps}^{[29]}$ as the positron annihilation lifetime at dislocations. The $\tau_{2}$ for the $\left[0 \mathrm{H}+3.3\right.$ pct $\left.\varepsilon_{\mathrm{p}}\right]$ and $\left[0.5 \mathrm{H}+3.3\right.$ pct $\left.\varepsilon_{\mathrm{p}}\right]$ specimens were fixed at $157 \mathrm{ps}$ in order to discuss the 
positron lifetime and its intensity of vacancy-type defects as the third component.

As shown in Table II, $\tau_{3}$ for the $\left[0 \mathrm{H}+3.3\right.$ pct $\left.\varepsilon_{\mathrm{p}}\right]$ specimen was 304 ps and $\tau_{3}$ for the $\left[0.5 \mathrm{H}+3.3\right.$ pct $\left.\varepsilon_{\mathrm{p}}\right]$ specimens were 349, 382, and 404 ps, respectively. The relative intensity of the third component, $I_{3}$, for the $\left[0 \mathrm{H}+3.3\right.$ pct $\left.\varepsilon_{\mathrm{p}}\right]$ specimen was 8.1 pet and $I_{3}$ for the $\left[0.5 \mathrm{H}+3.3\right.$ pct $\left.\varepsilon_{\mathrm{p}}\right]$ specimens was $6.6,7.4$, and 8.1 pct, respectively. $\tau_{3}$ for the $\left[0.5 \mathrm{H}+3.3\right.$ pct $\left.\varepsilon_{\mathrm{p}}\right]$ specimens was longer than that for the $\left[0 \mathrm{H}+3.3\right.$ pct $\left.\varepsilon_{\mathrm{p}}\right]$ specimen, although $I_{3}$ for the $\left[0.5 \mathrm{H}+3.3\right.$ pet $\left.\varepsilon_{\mathrm{p}}\right]$ specimens was at a comparable level to $I_{3}$ for the $\left[0 \mathrm{H}+3.3\right.$ pct $\left.\varepsilon_{\mathrm{p}}\right]$ specimen. Based on the calculation carried out by Ohkubo et al., ${ }^{[27]} \tau_{3}$ for the $\left[0 \mathrm{H}+3.3\right.$ pct $\left.\varepsilon_{\mathrm{p}}\right]$ specimen corresponds to the positron lifetime of clustered vacancies in the range from $\mathrm{V}_{9}$ to $\mathrm{V}_{15}$, whereas $\tau_{3}$ for $[0.5$ $\mathrm{H}+3.3$ pct $\varepsilon_{\mathrm{p}}$ ] specimens is equivalent to that in the range from $V_{15}$ to $V_{51}$. Considering the L-TDS results for broad hydrogen desorption from vacancy-type defects, it is assumed that vacancy-type defects formed that had different binding energies with hydrogen or various thermal stabilities. In previous reports, the binding energy of mono-vacancies with hydrogen was 46 and $51 \mathrm{~kJ} \mathrm{~mol}^{-1[31,32]}$ and that of vacancy clusters was $68 \mathrm{~kJ} \mathrm{~mol}^{-1}$ [32] $^{\text {It }}$ has also been reported that vacancy-type defects induced by plastic deformation in pure iron can diffuse and agglomerate upon heating at $473 \mathrm{~K}$, resulting in residual thermally stable vacancy clusters. ${ }^{[19]}$ Therefore, while $\tau_{3}$ is single exponential decay component value, in fact, the $\left[0 \mathrm{H}+3.3\right.$ pct $\left.\varepsilon_{\mathrm{p}}\right]$ and $\left[0.5 \mathrm{H}+3.3\right.$ pct $\left.\varepsilon_{\mathrm{p}}\right]$ specimens presumably contained various sizes of vacancy-type defects, : ranging from $V_{1}$ to around $V_{15}$ for the $\left[0 \mathrm{H}+3.3\right.$ pct $\left.\varepsilon_{\mathrm{p}}\right]$ specimen and $V_{1}$ to around $V_{51}$ for the $[0.5 \mathrm{H}+3.3$ pct $\left.\varepsilon_{\mathrm{p}}\right]$ specimen. This implies that larger vacancy-type defects formed and remained from the diffusion and agglomeration of mono-vacancies. In other words, the PAS results clearly indicate that for the $[0.5 \mathrm{H}+3.3$ pct $\varepsilon_{\mathrm{p}}$ ] specimen subjected to plastic strain in the presence of hydrogen, the formation of vacancy-type defects was enhanced more than for the $[0 \mathrm{H}+3.3 \mathrm{pct}$ $\varepsilon_{\mathrm{p}}$ ] specimen subjected to plastic strain in the absence of hydrogen; the formation of vacancy-type defects were enhanced by hydrogen. This conclusion is consistent with previously reported results for plastic-strained pure iron $^{[20]}$ and austenitic stainless steels ${ }^{[21]}$ in the presence of hydrogen.
B. Effects of Plastic Straining and Amount of Initial Hydrogen on the Formation of Strain-Induced Lattice Defects Enhanced by Hydrogen

An increase in the amount of plastic strain and initial hydrogen promoted more tracer hydrogen desorption from plastic-strained specimens in the presence of hydrogen. This means that plastic straining and the amount of hydrogen accelerated the formation of hydrogen-enhanced lattice defects, i.e., mono-vacancies and vacancy clusters. The effect of the amount of plastic strain on vacancy formation was especially more dominant than that of the amount of hydrogen.

Here, we will discuss the reasons for this according to the mechanism by which the formation of vacancy-type defects is enhanced by hydrogen. The following three factors multiply the nucleation of vacancy-type defects enhanced by hydrogen.

(I) Local nucleation of vacancy-type defects by plastic strain

(II) Enhancement of the nucleation and the stabilization of vacancy-type defects by hydrogen.

(III) Local diffusion and agglomeration of hydrogen by stress application

Firstly, with regard to factor (I), it is well known that vacancy-type defects can form in the absence of hydrogen as a result of the dislocation dynamics in plastic deformation, i.e., the coalescence of edge dislocations with opposite characteristics located on slip planes apart from an atomic plane ${ }^{[33]}$ and the interaction and cutting of screw dislocations. ${ }^{[34]}$ Nagao et al. studied the accumulation of dislocations beneath the fracture surface of quasi-brittle fractured lath martensitic steel by using transmission electron microscopy. They observed slip bands and dislocation cells with high density dislocations beneath the fracture surface, ${ }^{[12]}$ where it has been reported that vacancy-type defects locally formed. ${ }^{[35]}$ In this study, excess vacancy-type defects could also have formed in a region of high density of dislocations, like slip bands and dislocation cells, beneath the quasi-cleavage fracture surface since the specimens had a lath martensitic microstructure like the specimens used by Nagao et al.

Secondly, we will explain factor (II). Vacancy-type defects in excess of the thermal equilibrium concentration are generally annihilated at room temperature. However, Kirchheim proposed a thermodynamics

Table II. Three-Components Analysis of Positron Lifetime Spectra for $[0 \mathrm{H}],\left[0 \mathrm{H}+3.3\right.$ pct $\left.\varepsilon_{\mathrm{p}}\right]$, and $\left[0.5 \mathrm{H}+3.3\right.$ pct $\left.\varepsilon_{\mathrm{p}}\right]$ Specimens; $\tau_{2}$ Value for $\left[0 \mathrm{H}+3.3\right.$ pet $\left.\varepsilon_{\mathrm{p}}\right]$ and $\left[0.5 \mathrm{H}+3.3 \mathrm{pct} \varepsilon_{\mathrm{p}}\right]$ Specimens Is Fixed at $157 \mathrm{ps}\left(157_{\mathrm{F}}\right)$

\begin{tabular}{|c|c|c|c|c|c|c|c|c|}
\hline & $\tau_{\mathrm{m}}(\mathrm{ps})$ & $\tau_{1}(\mathrm{ps})$ & $\tau_{2}(\mathrm{ps})$ & $\tau_{3}(\mathrm{ps})$ & $I_{1}(\mathrm{Pct})$ & $I_{2}(\mathrm{Pct})$ & $I_{3}(\mathrm{Pct})$ & $\chi^{2} / q$ \\
\hline$[0 \mathrm{H}]$ & 140 & 75.6 & 157 & 571 & 23.5 & 75.9 & 0.6 & 1.07 \\
\hline$\left[0 \mathrm{H}+3.3\right.$ pct $\left.\varepsilon_{\mathrm{p}}\right]$ & 160 & 77.7 & $157 \mathrm{~F}$ & 304 & 8.6 & 83.4 & 8.1 & 1.06 \\
\hline$\left[0.5 \mathrm{H}+3.3\right.$ pct $\left.\varepsilon_{\mathrm{p}}\right]-$ No. 1 & 169 & 54.8 & $157 \mathrm{~F}$ & 404 & 4.5 & 88.1 & 7.4 & 1.12 \\
\hline$\left[0.5 \mathrm{H}+3.3\right.$ pct $\left.\varepsilon_{\mathrm{p}}\right]-$ No. 2 & 166 & 43.5 & $157 \mathrm{~F}$ & 349 & 3.8 & 88.1 & 8.1 & 1.02 \\
\hline$\left[0.5 \mathrm{H}+3.3\right.$ pct $\left.\varepsilon_{\mathrm{p}}\right]-$ No. 3 & 165 & 69.8 & $157 \mathrm{~F}$ & 382 & 6.2 & 87.2 & 6.6 & 1.08 \\
\hline
\end{tabular}


model in which hydrogen accelerates the nucleation of vacancy-type defects. ${ }^{[36,37]}$ In this concept, solute hydrogen atoms lower the formation energy of vacancy-type defects and thereby excess vacancy-type defects form. Matsumoto et al. calculated that vacancy-type defects stably exist due to hydrogen trapping and the formation of complexes with hydrogen. ${ }^{[38]}$ In this study, hydrogen enhanced the formation of vacancy-type defects in the process of plastic deformation and excess vacancy-type defects were stable as a result of trapping hydrogen.

Regarding factor (III), solute hydrogen atoms probably accumulate at stress concentration regions. Cracks in lath martensitic steel exhibiting quasi-cleavage fracture caused by HE propagated approximately along the lath boundaries, ${ }^{[12,39]}$ where intense slip bands and dislocation cells were observed. ${ }^{[12]}$ It is assumed that the application of stress up to $1400 \mathrm{MPa}$ prior to tensile strength to specimens causes necking locally, resulting in stress concentration as mentioned above. It is well known that tensile stress reduces the chemical potential of hydrogen, leading to an increase in solute hydrogen concentration. ${ }^{[40]}$ In this study, as a result of factors (I) and (II), the excess vacancy-type defects that formed presumably accumulated locally and then existed stably at room temperature as vacancy clusters. Furthermore, factor (III) of local hydrogen accumulation due to stress application probably promotes factor (II) of local vacancy accumulation.

Taking into consideration the discussion above, we will discuss the change in the amount of vacancy-type defects enhanced by hydrogen at the stage of elastic and early plastic deformation and final fracture in Figure 5(a). In the stage of elastic and early plastic deformation, tracer hydrogen desorption corresponding to lattice defects is presumably less since dislocation slips partially occur and fewer vacancy-type defects form. On the other hand, not only edge dislocations but also screw dislocations can move prior to final fracture in the later stage of uniform elongation in tempered martensitic steel with body-centered cubic lattices. It is suggested that tracer hydrogen desorption corresponding to vacancy-type defects enhanced by hydrogen significantly increases as a result of nucleation of excess vacancy-type defects by the dynamic interaction of dislocations. As shown in Figure 5(b), tracer hydrogen desorbed in the low-temperature range corresponding to these vacancy defects with an increasing amount of initial hydrogen. This implies that nucleated vacancy -type defects have lower binding energy with hydrogen or remain as relatively smaller and less thermally stable defects. The formation energy of vacancy-type defects for the $\left[4.0 \mathrm{H}+1.3 \mathrm{pct} \varepsilon_{\mathrm{p}}\right]$ specimen was reduced compared with the $\left[0.5 \mathrm{H}+1.3\right.$ pct $\left.\varepsilon_{\mathrm{p}}\right]$ specimen because the former specimen had more initial hydrogen than the latter specimen. For the $\left[4.0 \mathrm{H}+1.3\right.$ pct $\left.\varepsilon_{\mathrm{p}}\right]$ specimen, more vacancy-type defects formed at the same level of plastic strain. Therefore, an increase in the amount of plastic strain promoted the nucleation frequency of vacancy-type defects enhanced by hydrogen. In addition, an increase in the amount of initial hydrogen assisted the formation and stability of vacancy-type defects.

\section{Accumulation of Strain-Induced Lattice Defects Enhanced by Hydrogen at Final Fracture Stage}

As shown in Figures 6(a) and (b), the amount of tracer hydrogen for the $\left[0.5 \mathrm{H}+3.3 \mathrm{pct} \varepsilon_{\mathrm{p}}\right]$ specimens markedly increased in the region $1.5 \mathrm{~mm}$ distant from the fracture surface. As discussed in Sections IV-A and IV-B, this increase contributed to the formation of vacancy-type defects enhanced by hydrogen. One key finding is that an increase in tracer hydrogen desorption was observed not only in the high-temperature range approximately $371 \mathrm{~K}$, but also at a low temperature approximately $330 \mathrm{~K}$. This finding implies that smaller size of vacancy-type defects, which have lower binding energy with hydrogen or less thermally stable, formed notably beneath the fracture surface. This formation of vacancy-type defects was discussed in Section IV-B. According to the stress-displacement curves of the [0.5 $\mathrm{H}]$ and $[4.0 \mathrm{H}]$ specimens in Figure 2, final fracture occurred immediately after reaching maximum tensile strength. This indicates that plastic instability occurred as a result of reaching the critical concentration of accumulated vacancy-type defects. Considering the difference in the amount of tracer hydrogen between the $\left[0 \mathrm{H}+3.3\right.$ pct $\left.\varepsilon_{\mathrm{p}}\right]$ and $\left[0.5 \mathrm{H}+3.3\right.$ pct $\left.\varepsilon_{\mathrm{p}}\right]$ specimens as the amount of tracer hydrogen corresponding to vacancy-type defects, it was 1.2 mass ppm at the fracture surface region. The result shows that ductility loss occurred in the tempered martensitic steel specimens due to HE. The concentration of vacancy-type defects corresponding to this amount of tracer hydrogen is a necessarily requisite value for causing this ductility loss.

When a mono-vacancy traps one or two hydrogen atoms, they are in the most stable energy state. ${ }^{[41]}$ Assuming that a mono-vacancy traps one or two hydrogen atoms, we will calculate the concentration of vacancy-type defects. The concentrations of vacancy-type defects in terms of the atomic ratio for the $\left[0.5 \mathrm{H}+3.3\right.$ pct $\left.\varepsilon_{\mathrm{p}}\right]$ specimen at the fracture surface were calculated as $6.72 \times 10^{-5}$ and $3.36 \times 10^{-5}$ for Vac.-H and Vac. $-\mathrm{H}_{2}$, respectively. These values are much higher than the thermal equilibrium concentration of mono-vacancies at room temperature. Tamura et al. studied the recovery process of annealing plastic-strained low carbon steel by using electrical resistance measurement. They reported vacancy-type defects of approximately $4 \times 10^{-5}$ nucleated by applying plastic strain of 20 pct at $198 \mathrm{~K}^{\left[{ }^{[42]}\right.}$ It was found that vacancy-type defects comparable to the specimen above formed under the application of plastic strain of only 3.3 pct in the presence of hydrogen. In other words, it implies that applying even a small amount of plastic strain in the presence of hydrogen reaches the critical concentration of vacancy-type defects. Subsequently, crack is expected to initiate in the region where vacancy-type defects are in a critical concentration because of (a) nanovoid nucleation and coalescence or (b) lattice instability. ${ }^{[43,44]}$ Needleman and Tvergaard proposed a model in which high density nucleated microvoids reduce the stress-carrying capacity at the crack tip. ${ }^{[43]}$ Neeraj et al. observed the formation of nanoscale dimples $(\leqq 20 \mathrm{~nm})$ at a brittle fracture surface in hydrogen-charged ferritic steel 
by using high-resolution transmission electron micrography. ${ }^{[45]}$ This model and experimental results support concept (a). On the other hand, excess vacancy-type defects may lower the lattice instability. ${ }^{[44]}$ This is consistent with the amorphization observed at the front of a crack in hydrogen-charged steel. ${ }^{[46]}$ Subsequently, a crack can propagate by the repeated occurrence of (a) or (b) above, resulting in final fracture. In a finite element analysis, a crack presumably propagates as a result of void density reaching a critical level due to shear localization in front of the crack tip. ${ }^{[47]}$ The present results related to the process from crack initiation to crack propagation agree well with these previous reports.

To summarize, plastic straining forms excess vacancy-type defects in the presence of hydrogen at room temperature, which are stabilized by hydrogen trapping at local stress-concentrated region. It causes a high density of accumulated vacancy-type defects to reach a critical level of nanovoid nucleation and coalescence, resulting crack initiation. The mechanism of crack propagation resulting in quasi-cleavage fracture was discussed in the context of the previous reports.

\section{CONCLUSION}

In this work, an effort was made to separate the hydrogen peaks desorbed from hydrogen-enhanced lattice defects from among various trapping sites in tempered martensitic steel showing quasi-cleavage fracture by using L-TDS. The kind of lattice defects was identified by using PAS. In addition, the effect of the amount of plastic strain and initial hydrogen on the formation of hydrogen-enhanced lattice defects was examined by L-TDS. The amount of nucleated hydrogen-enhanced lattice defects was examined by L-TDS to understand the accumulation process of hydrogen-enhanced lattice defects until final fracture in the quasi-cleavage fracture mode.

1. L-TDS made it possible to separate two peaks, specifically, two peak desorption temperatures of approximately $293 \mathrm{~K}$, and $371 \mathrm{~K}$ as a result of subjecting steel specimens to plastic strain in the presence of hydrogen. Hydrogen desorption at a peak temperature of approximately $293 \mathrm{~K}$ was commonly observed in plastic-strained specimens and the amount was almost equal whether in the presence or absence of hydrogen. Desorption was also measured at the same desorption temperature for a non-strained specimen containing dislocations. In contrast, a new hydrogen desorption at peak temperature of approximately $371 \mathrm{~K}$ was measured for a specimen subjected to plastic strain in the presence of hydrogen. This desorption corresponded to hydrogen-enhanced lattice defects.

2. PAS results revealed that plastic straining increased the mean positron lifetime, indicative of the formation of dislocations and some vacancy-type defects as deformation-induced lattice defects. Incremental mean positron lifetime was observed by plastic straining in the presence of hydrogen. Together with the L-TDS result showing no change in hydrogen desorption corresponding to dislocations for plastic strain with/without hydrogen, the hydrogen-enhanced lattice defects were vacancy-type defects, i.e., mono-vacancies and vacancy clusters.

3. A further increase in the amount of plastic strain and the amount of initial hydrogen at straining promoted the formation of vacancy-type defects. It was found that the amount of plastic strain had a greater effect on this formation than the amount of initial hydrogen at straining.

4. Vacancy-type defects formed in a region $1.5 \mathrm{~mm}$ distant from the quasi-cleavage fracture surface markedly increased and the amount of tracer hydrogen corresponding to vacancy-type defects reached 1.2 mass ppm at the fracture surface. Assuming that a mono-vacancy traps one or two hydrogen atoms, the mean concentration of vacancy-type defects was calculated as approximately $3.0 \times 10^{-5}-6 \times 10^{-5}$ in terms of atomic ratio. Therefore, the process of quasi-cleavage fracture can be explained as early crack initiation leading to final fracture as a result of reaching a critical level of locally accumulated excess vacancy-type defects enhanced by hydrogen even for a small amount of plastic strain.

\section{REFERENCES}

1. W.W. Gerberich and Y.T. Chen: Metall. Mater. Trans. A, 1975, vol. 6 A, pp. 271-78.

2. J.P. Hirth: Metall. Mater. Trans. A, 1980, vol. 11A, pp. 861-90.

3. H.K. Birnbaum and P. Sofronis: Mater. Sci. Eng. A, 1994, vol. 176, pp. 191-202.

4. I.M. Robertson and H.K. Birnbaum: Acta Mater., 1986, vol. 34, pp. 353-66.

5. M.L. Martin, M. Dadfarnia, A. Nagao, S. Wang, and P. Sofronis: Acta Mater., 2019, vol. 165, pp. 734-50.

6. M. Nagumo, M. Nakamura, and K. Takai: Metall. Mater. Trans. A, 2001, vol. 32A, pp. 339-47.

7. M. Nagumo: Mater. Sci. Technol., 2004, vol. 20, pp. 940-50.

8. M. Nagumo and K. Takai: Acta Mater., 2019, vol. 165, pp. 722-33.

9. Y. Matsumoto, K. Takai, M. Ichiba, T. Suzuki, T. Okamura, and S. Mizoguchi: ISIJ Int., 2013, vol. 53, pp. 714-22.

10. Y. Matsumoto and K. Takai: Metall. Mater. Trans. A, 2018, vol. 49A, pp. 490-97.

11. T. Doshida, H. Suzuki, K. Takai, N. Oshima, and T. Hirade: ISIJ Int., 2012, vol. 52, pp. 198-207.

12. A. Nagao, C.D. Smith, M. Dadfarnia, P. Sofronis, and I.M. Robertson: Acta Mater., 2012, vol. 60, pp. 5182-89.

13. Y. Matsumoto and K. Takai: Metall. Mater. Trans. A, 2017, vol. 48A, pp. 666-77.

14. M. Hattori, H. Suzuki, Y. Seko, and K. Takai: JOM, 2017, vol. 69 , pp. 1375-80.

15. K. Takai, H. Shoda, H. Suzuki, and M. Nagumo: Acta Mater., 2008, vol. 56, pp. 5158-67.

16. N. Abe, H. Suzuki, K. Takai, N. Ishikawa, and H. Sueyoshi: Materials Science and Technology Conference and Exhibition 2011, 2011, MS \& T'11, pp. 1277-84.

17. T. Doshida and K. Takai: Acta Mater., 2014, vol. 79, pp. 93-107.

18. P. Hautojärvi: Topics in Current Physics, Springer, Berlin, 1979, vol. 12 , pp. $1-23$ 
19. A. Vehanen, P. Hautojärvi, J. Johanson, J. Yli-Kauppila, and P. Moster: Phys. Rev. B, 1982, vol. 25, pp. 762-80.

20. K. Sakaki, T. Kawase, M. Hirato, M. Mizuno, H. Araki Y. Shirai, and M. Nagumo: Scr. Mater., 2006, vol. 55, pp. 1031-34.

21. M. Hatano, M. Fujinami, K. Arai, H. Fujii, and M. Nagumo: Acta Mater., 2014, vol. 67, pp. 342-53.

22. H. Saito, Y. Nagashima, T. Kuriharab, and T. Hyodo: Nucl. Instrum. Methods, 2002, vol. 487, pp. 612-17.

23. P. Kirkegaard, J. V. Olsen, M. M. Eldrup, and N. J. Pedersen: PALSfit, A computer program for analysing positron lifetime spectra, Denmark. Forskningscenter Risoe. Risoe-R, no. 1652(EN), Danmarks Tekniske Universitet, Risø Nationallaboratoriet for Bæredygtig Energi, Roskilde, 2009.

24. M. Nagumo, K. Takai, and N. Okuda: J. Alloys Compd., 1991, vols. 293-295, pp. 310-16.

25. R.A. Oriani: Acta Mater., 1970, vol. 18, pp. 147-57.

26. M.J. Puska and R.M. Nieminen: Rev. Mod. Phys., 1994, vol. 66, pp. 841-97.

27. H. Ohkubo, Z. Tang, Y. Nagai, M. Hasegawa, T. Tawara, and M. Kiritani: Mater. Sci. Eng. A, 2003, vol. 350, pp. 95-101.

28. C. Hidalgo, G. Gonzalez-Doncel, S. Linderoth, and J. San Juan: Phys. Rev. B, 1992, vol. 13, pp. 7017-21.

29. M. Yoshida, T. Asano, Y. Fujishiro, and Y. Shirai: Tetsu-to-Hagan, 2005, vol. 91, pp. 403-07.

30. R.N. Gardner and H.G.F. Wilsdorf: Metall. Trans. A, 1980, vol. A11, pp. 659-69.

31. S.M. Myers, S.T. Picraux, and R.E. Stoltz: Jpn. J. Appl. Phys., 1979, vol. 50, pp. 5710-19.

32. S.M. Myers, D.M. Follsteaedt, F. Besenbacher, and J. Bottiger: Jpn. J. Appl. Phys., 1982, vol. 53, pp. 8734-44.
33. U. Essmann and H. Mughrabi: Philos. Mag., 1979, vol. 40, pp. 731-56.

34. A.M. Cuitino and M. Ortiz: Acta Mater., 1996, vol. 44, pp. 427-36.

35. R.H. Van Stone, T.B. Cox, J.R. Low, and J.A. Psioda: Int. Mater. Rev., 1985, vol. 39, pp. 157-80.

36. R. Kirchheim: Acta Mater., 2007, vol. 55, pp. 5129-38.

37. R. Kirchheim: Acta Mater., 2007, vol. 55, pp. 5139-48.

38. R. Matsumoto, N. Nishiguchi, S. Taketomi, and N. Miyazaki: $J$. Soc. Mater. Sci. Jpn., 2014, vol. 63, pp. 182-87.

39. A. Shibata, H. Takahashi, and N. Tsuji: ISIJ Int., 2012, vol. 52, pp. 208-12.

40. J.O’M. Bockris, W. Beck, M.A. Genshaw, P.K. Subramanyan, and F.S. Williams: Acta Mater., 1971, vol. 19, pp. 1209-18.

41. Y. Tateyama and T. Ohno: Phys. Rev. B, 2003, vol. 67, pp. 174105-13

42. J. Takamura, I. Takahashi, and M. Amano: Trans. ISIJ., 1969, vol. 9, pp. 216-21

43. A. Needleman and V. Tvergaard: J. Mechan. Phys. Solids, 1987, vol. 35, pp. 151-83.

44. R.W. Cahn: Nature, 1978, vol. 273, pp. 491-92.

45. T. Neeraj, R. Srinivasan, and J. Li: Acta Mater., 2012, vol. 60, pp. $5160-71$.

46. M. Nagumo, T. Ishikawa, T. Endoh, and Y. Inoue: Scr. Mater., 2003, vol. 49, pp. 837-42.

47. M. Nagumo, H. Yoshida, Y. Shimomura, and T. Kadokura: Mater. Trans., 2001, vol. 42, pp. 132-37.

Publisher's Note Springer Nature remains neutral with regard to jurisdictional claims in published maps and institutional affiliations. 